\title{
FROM RESILIENCE TO FLEXIBILITY: URBAN SCENARIO TO REDUCE HAZARD
}

\author{
ROBERTO DE LOTTO, VERONICA GAZZOLA CECILIA MORELLI DI POPOLO \& \\ ELISABETTA MARIA VENCO \\ Department of Civil Engineering and Architecture - UPLab - University of Pavia.
}

\begin{abstract}
Population estimates and projections demonstrate that, in the next future, human beings, buildings, economy and society will be exposed to multiple effects (direct and indirect) of phenomena capable of producing temporary and permanent damages on natural environment. The city, as complex system, in case of slow changes, is able to modify its main components and relations (physical and social). During and after unexpected disasters (i.e. floods, earthquakes, hurricanes, terrorist attacks, etc.), its ability to absorb external impacts, to transform and to adapt itself in order to find a new equilibrium status, is particularly stressed and involves the concept of resilience.

To be resilient, town should change unceasingly to adapt to the continuous modification of citizens and environment demands and to find a new balance in different dimensions (flexible city).

The paper aims to give some strategically recommendations that will contribute to reduce disaster risk at urban level. Investigating the future of urbanization and of urban theory, the authors try to rethink the city as a dynamic space that better responds to evolving circumstances and contemporary global challenges: concepts of resilient and flexible cities are involved.

Keywords: advanced hazard planning, complex system, flexible city, risk reduction, scenario planning, urban resilience.
\end{abstract}

\section{INTRODUCTION}

At the beginning of 20 th century, $10 \%$ of the worldwide population lived in cities. The number of urban inhabitants increased in the XX and XXI century (reaching about 50\% in 2013) and it will rise still over the next three decades: it has been estimated that in 2050, $75 \%$ of worldwide population will live in cities [1]. The exponential growth of urbanization depending on human presence and the intensification and diversification of land-use practices and patterns (especially in low-income and developing countries) lead to cities to be exposed to multiple effects of different events both man-made (i.e. civil disorders, industrial accidents, terrorism, wars) and natural (i.e. earthquakes, volcanic activity, storms, floods, landslides). These events may become disasters (hazardous events that occur over a limited time span in a defined area) or catastrophes (massive disasters that require significant expenditure of money and a long time for recovery to take place) in relation to the exposure of population and its physical and economic assets.

It can react to hazardous phenomena trying to mitigate effects and consequences that these events produce on natural environment, buildings, human beings, economy and society or trying to absorb external impacts, transform and adapt itself, finding a new balance [2]. Land-use planning that limits construction in hazardous locations, hazard-resistant construction, and hazard modification or control, which are some of the adjustments that anticipate future disastrous events, may reduce vulnerability to them. Moreover, cities should change unceasingly to adapt 
to the continuous modification of citizens and environment demands. These actions together reduce the possibility that a disaster produces irreversible disruptions on a global ecosystem.

The authors give different approaches with some utopian and realistic applications involving concepts of resilient and flexible cities.

\section{RESILIENT CITY}

The ability to adapt, deal and cope with different kind of hazards is necessary to develop resilient cities. 'Such cities would be capable of withstanding severe shock without either immediate chaos or permanent harm. Designed in advance to anticipate, weather and recover from the impacts of natural or terrorist hazards, resilient cities would be built on principles derived from past experience with disasters in urban areas. While they might bend from hazard forces, they would not break. Composed of networked social communities and lifeline systems, resilient cities would become stronger by adapting and learning from disasters' [3].

So, resilience could be read as a new way to understand and manage urban planning with particular reference to hazards.

In literature, related to the different meanings and contexts in which resilience develops, there are several definitions:

- 'Social resilience is the ability of groups or communities to cope with external stresses and disturbances as a result of social, political and environmental change [...] ability of communities to withstand external shocks to their social infrastructure' [4];

- 'Amount of change a system can undergo without changing state' [5];

- 'The ability of a system to absorb perturbations or stresses without changes in its fundamental structure or function that would drive the system into a different state' [6];

- 'The ability of a system to recover from the effect of an extreme load that may have caused harm' [7];

- 'The capacity of a system, community or society potentially exposed to hazards to adapt, by resisting or changing in order to reach and maintain an acceptable level of functioning and structure' [8];

- 'Refers to three conditions that enable social or ecological systems bounce back after a shock. The conditions are: ability to self-organize, ability to buffer disturbance and capacity for learning and adapting' [9];

- 'Resilience is the ability of a system, community, or society exposed to hazards to resist, absorb, accommodate to and recover from the effects of a hazard in a timely and efficient manner' [10];

- 'Building resilience is about making people, communities and systems better prepared to withstand catastrophic events - both natural and manmade - and able to bounce back more quickly and emerge stronger from these shocks and stresses' [11].

Moreover, many researchers have defined the main principles of resilience. In particular:

- Foster [12] proposed 31 principles for achieving resilience and organized them in several categories: General systems (significance of internal variables, impact of external variables, diversity of components, functional redundancy), Physical (not site specific, fine grained and modular, standardization, mobile, no esoteric components, unique skills unnecessary, stable, fail-safe design, early fault detection), Operational (efficient, reversible, incremental operation, autonomous operation), Timing (short lead time and rapid response to stimuli, open-end life span), Social (compatibility with diverse value sys- 
tems; capacity to satisfy several goals; equitable distribution of benefits and costs; generous compensation for major losers; accessibility), Economic (incremental funding, wide range of potential financial support, high benefit-cost ratio, early return on investments, equitable division of benefits and costs) and Environmental (minimal adverse impacts, replenish able or extensive resource base);

- Godschalk [3] defined resilient systems to disasters as: Redundant (many functionally similar components, if one fails the entire system resists); Diverse (many functionally different components to cope with different threats); Efficient; Autonomous (capable to operate independently); Strong; Interdependent (connected system components supporting each other); Adaptable (flexible); Collaborative (multiple opportunities and incentives for stakeholder's participation);

- In Colucci [13] from Transition Cities by Hopkins [14], the following resilience concepts are underlined: diversity; redundancy; modularity; local-based policies and strategies; concept of small related to the balance between environmental, social and economic resources and their development and consumption grade. Moreover, visioning that is a positive approach to changes and objectives; social inclusion that means social ability to activate internal resources and ability to self-organization; construction of bottom-up processes and active sharing;

- Lewis and Conaty [15] defined seven main principles for resilient communities: Diversity of cultures (social and economic activity enhancing adaptation and innovation and reducing systemic collapse's risk); Modularity of elements (they can operate independently but are capable of functioning alongside); Social capital (ability of community members to respond collectively to challenges); Innovation (learning, exploration, adaptation, experimentation); Overlap (prioritization of redundancy over economic efficiency to minimize risks); Tight Feedback Loops (strong feedback loops to recognize social, ecological and economic thresholds); Ecosystem Service (importance of impacts of human activities on ecosystem) [16].

In the presented research, the resilience definition is linked to the ecological approach: in this meaning, it is the capacity of a given ecosystem to react to external shocks and to return to a state of balance (not necessarily the original one) and it is based on concepts of persistence, change, adaptability, variability and, eventually, flexibility.

The capacity of an urban area to be resilient depends on the organization and the relationships existing among the internal elements before the event: considering that a flexible system allows the rapid recovery of activities, flexibility approach helps to reach resilience goals [17-19].

\section{FLEXIBLE CITY}

The urban structure and the different subjects (common people, stakeholders, professionals, decision makers), require the ability to adapt to different and very quick modifications of external (global socio-economic environment) and internal (social and organizational scenario) conditions.

It is necessary that the material component of the city must adapt to the needs of the citizens and, as a consequence, to think about cities and territories as flexible environments. Therefore, flexibility is the adaptation to the social and economic conditions, the ability of the city to be efficient in a short time according to the demands of the context. This process involves city as an organism: the term is assumed as a development of the organic-adaptiveevolutionist approach to urban studies [20-22]. 
Flexibility is expressed in different dimensions, such as the flexibility of: relational systems (variable geometry); government systems; environmental system and ecological planning; predictive capacity of urban simulation; physical systems (in example functionalization and de-functionalization) and network structures. A Flexible city is efficient and smart, and it optimizes resources and, therefore, increases resilience.

It is possible to recognize different main themes linked to three principle dimensions: theoretical, related to the tangible city (physical part) and related to social phenomena [23, 24].

The main themes of flexible city are:

- Temporal Dimension: flexibility is meaningful if related to short, medium and long periods, which correspond to significant changes in the anthropological sense;

- Variable Geography: dimensions and physical shapes of cities (urbs) are not fixed a priori but they are the successful result of adaptation to all the changes occurred in civitas and polis;

- Reversibility: based on sustainability, any contraction of urban form should allow the re-naturalization of urban areas, considering the 'life cycle assessment' of the whole city and not just of each buildings;

- Functional un-differentiation: locally, the city must be able to adapt its functions and increase or reduce the urban load based on citizens and cities' needs without compromising the infrastructure system and the urban structure;

- Layer Structure: third dimension is essential to think about functional levels with different degrees of durability and adaptability;

- Ethero-organization: starting from general rules, it reaches balance between 'top-down' and auto-organization 'bottom-up' planning model.

\section{RESILIENCE AND FLEXIBILITY IN VULNERABLE ENVIRONMENT}

From the concepts of resilience and flexibility, some utopian exemplifications are identified (futuristic spaces, urban vision, models of city) to underline how these concepts can become elements of an urban project.

As defined by RIBA [25], authors identify three strategic approaches to hazardous events (especially those of natural origin): retreat, defend and attack.

'Retreat' means the repositioning of the vulnerable elements or of the entire city, in a more safe area. This is not a post event method: this is a long-term planned and managed process. In that way, the investments on existing building and infrastructure are stopped and are transferred on new communities. The most important expenditure is on social aspects. This situation occurs in the case of certain risks for some of their events, investing identifiable territories (some form of flooding, volcanic eruptions or tsunamis where it is possible to identify a vulnerable territory).

'Looking to a 100-year horizon of climate change predictions, we will address how the urban, built environment needs to react now. Conservative estimates predict sea-levels to continue to rise as the oceans warm and the ice caps melt. Coupled with isostatic rebound (the South sinking to the North) the effects grow ever more dramatic for large centers of population on the coast. Predicted weather patterns show increased rainfall intensity, leading to saver problems of surface water flooding in built up areas' [26].

Some futuristic project, based on this approach, are: from Kurokawa's Flooding city to the metabolistic approach of Tange to Tokyo, from Sea City to the float element of Buckminster Fuller, to many others. 


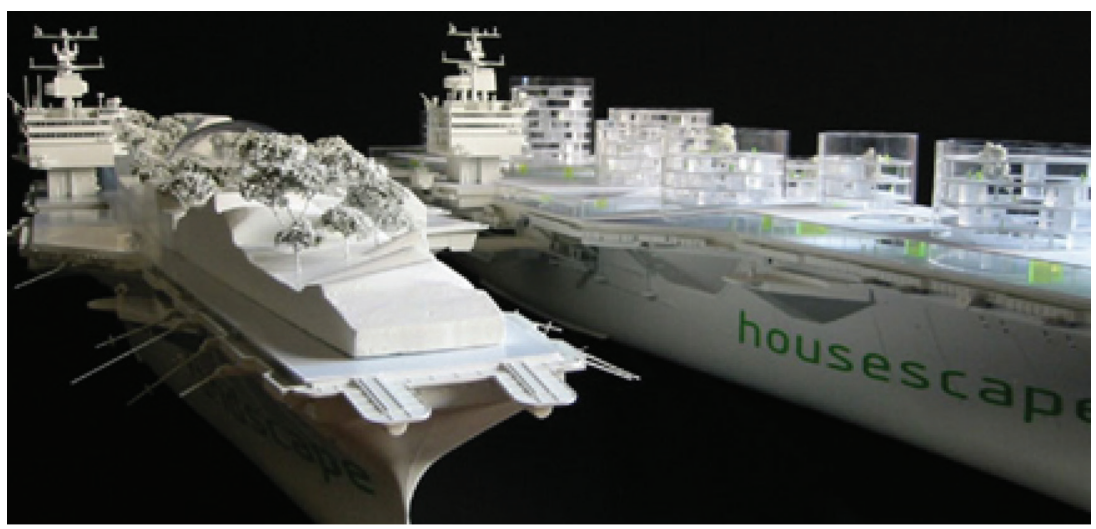

Figure 1: Micro-Utopie (iaN+ and Marco Garofalo, 2003).

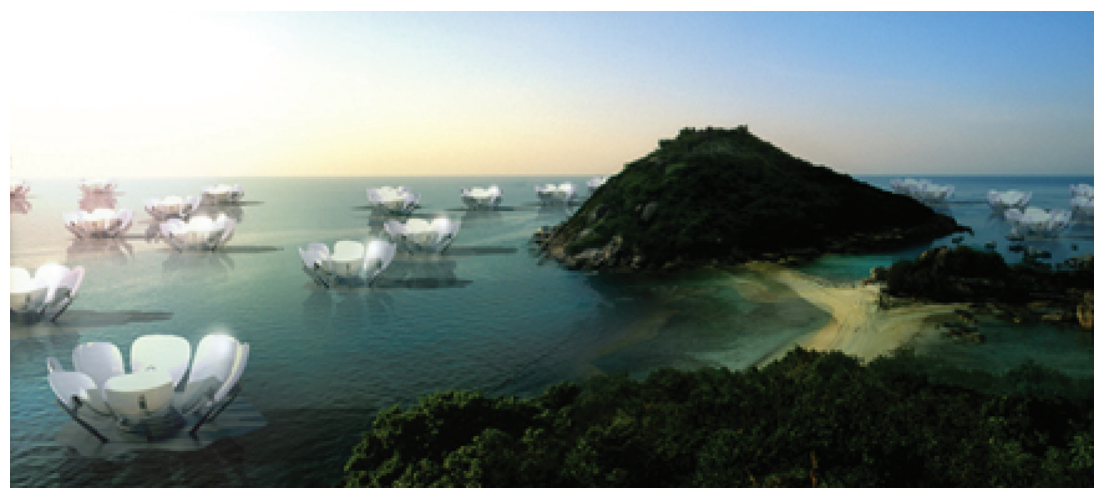

Figure 2: Giant Water Lilies (the Why Factory, 2008).

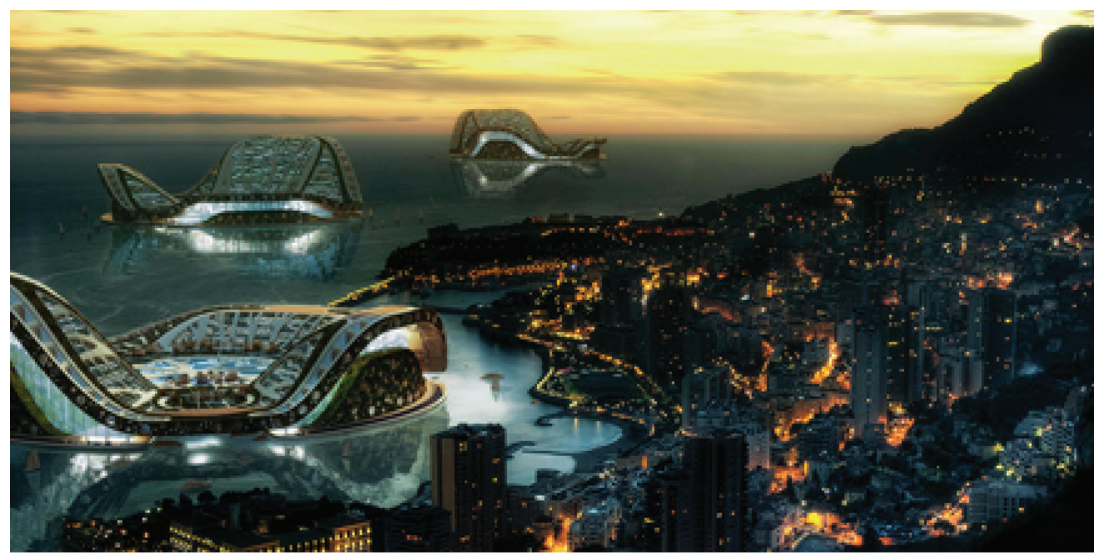

Figure 3: Lylipad (Vincent Callebaut Architecture, 2008). 
434 Urban Regeneration and Sustainability

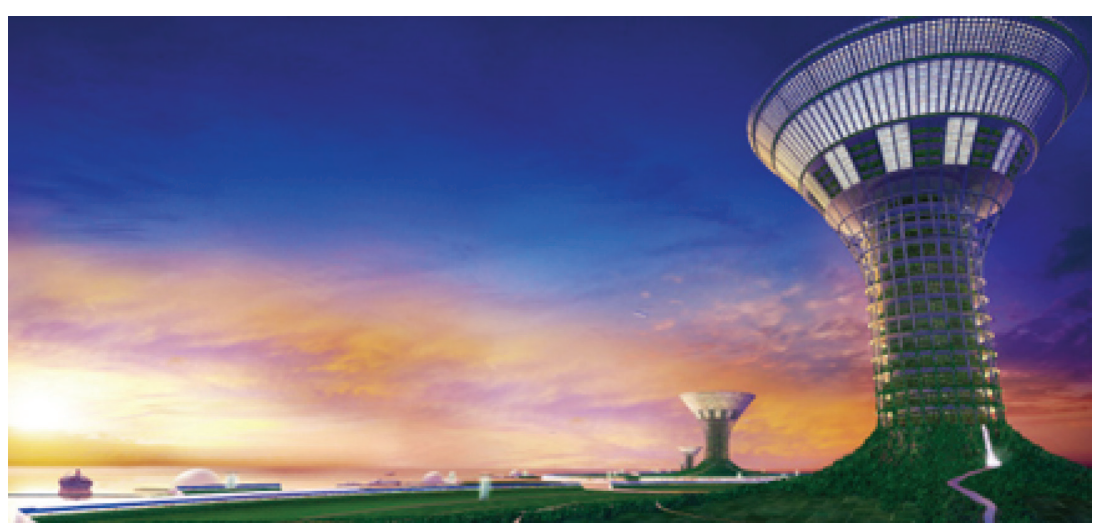

Figure 4: Green Float (Shimizu Corporation, 2010).

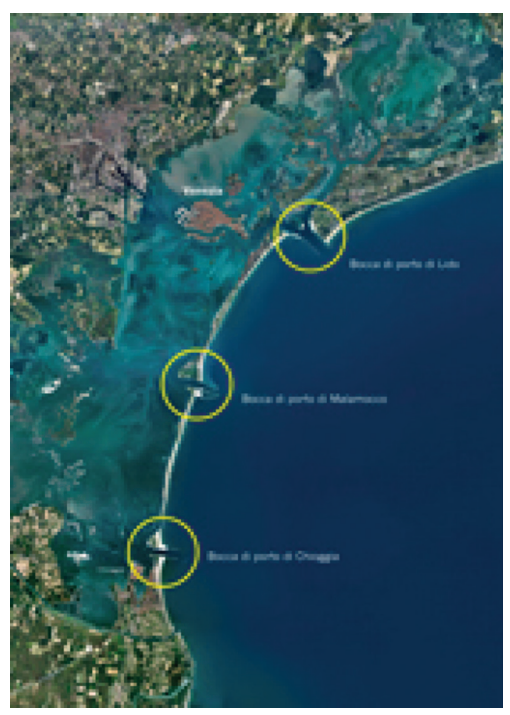

Figure 5: MOSE (MIT, 2003 - ongoing).

Micro-Utopie, by iaN+ and Marco Garofalo, 2003 [26], is based on the characteristic of adaptability that have the aircraft carrier to be offshore bases strategically positioned on the globe, for transform them into elements capable of supporting the needs of cities in case of risk. The functions can be different: artscape, housescape, sportscape, and landscape (Fig. 1).

Giant Water Lilies by the Why Factory (2008) [27] (Fig. 2), as Lylipad by Vincent Callebaut Architecture (2008) [26] (Fig. 3) or Green Float by Shimizu Corporation (2010) [26] (Fig. 4), transform a sort of various dimension floating platform in elements able to host people that leave mainland.

'Defense' strategy is related to the creation of a sort of barrier to the city to face disasters. This is a very expensive way to approach the problem and sometimes the environmental 


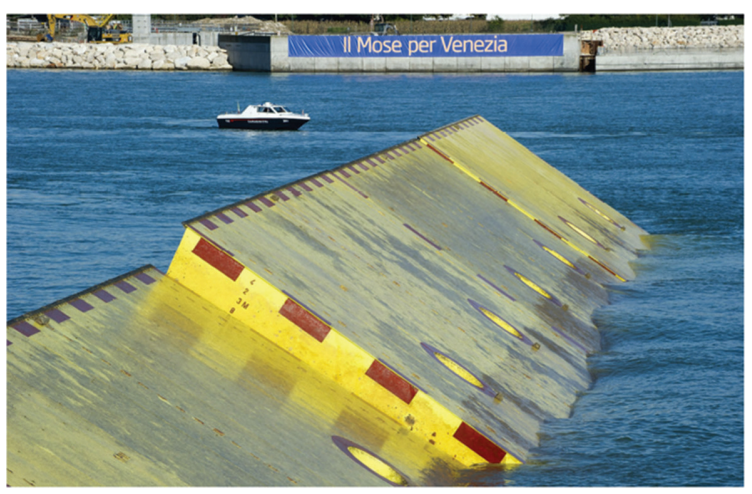

Figure 6: MOSE (MIT, 2003 - ongoing).
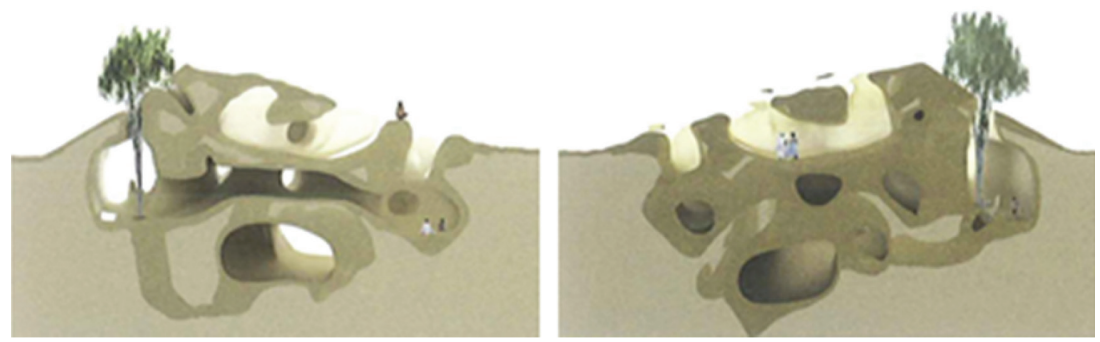

Figure 7: Dune (Magnus Larsson, 2007-08).

impact is too heavy, and not always solves the problem. This approach reduces a certain series of risks, deflecting it. Some example can be the MOSE project in Venice (Figs 5 and 6) by Ministero delle Infrastrutture e dei Trasporti (MIT), or the barriers in the Netherlands.

'Attack' means work with the problems and taking advantage from the consequences of the event as a basic element of urban planning. The type of risk is a core value within the range of approach to disaster. This method allows a longer living with the problem, an adaptation and transformation of the existing city and a change of elements at risk.

Dune, by Magnus Larsson (2007-08) [26] starting from the principle of manipulation of the landscape to help the people to live in an antagonistic environment, like the desert. In this project, a pathogen element (not harmful to humans); it is able to solidify the sand, forming caves and spaces to develop the underground land to become a whole town in the desert (Fig. 7). The project Flooded London, by Anthony Lau and the Bartlett School of Architecture (2008) [26], is a project research that imagine the future of London city after flooded disaster. The designer imagined a future floating city inside Thames, organized on unused oil-plant and on ship that needs to be demolish. (Fig. 8). The research project I-City/ We-City, by the Why Factory (2012) [27], is located in a post-catastrophe period. The research team introduces the question: 'What would the world look like if, after a series of natural disasters, the world was flooded and inhibition would be (almost) impossible? How could humanity survive?' (http://thewhyfactory.com/output/i-citywe-city/). An inquisitive 
Urban Regeneration and Sustainability

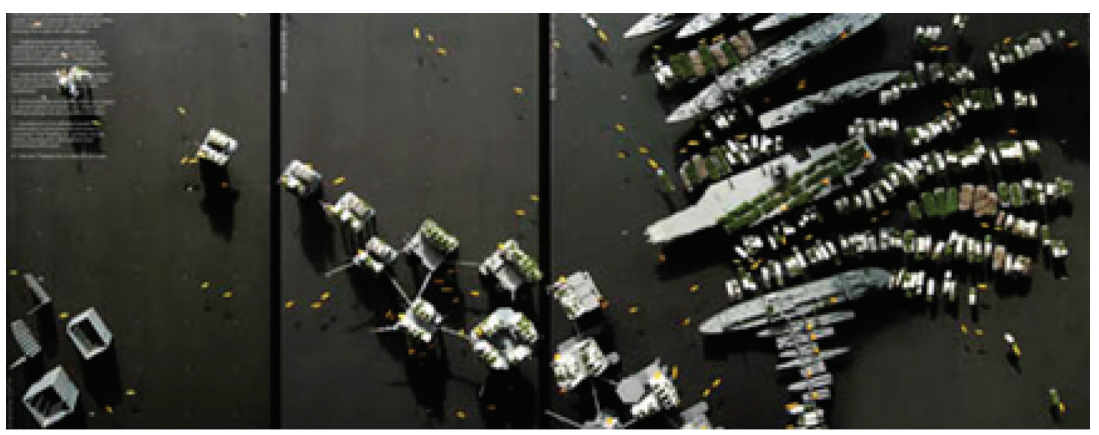

Figure 8: Flooded London (Anthony Lau, Bartlett School of Architecture, 2008).

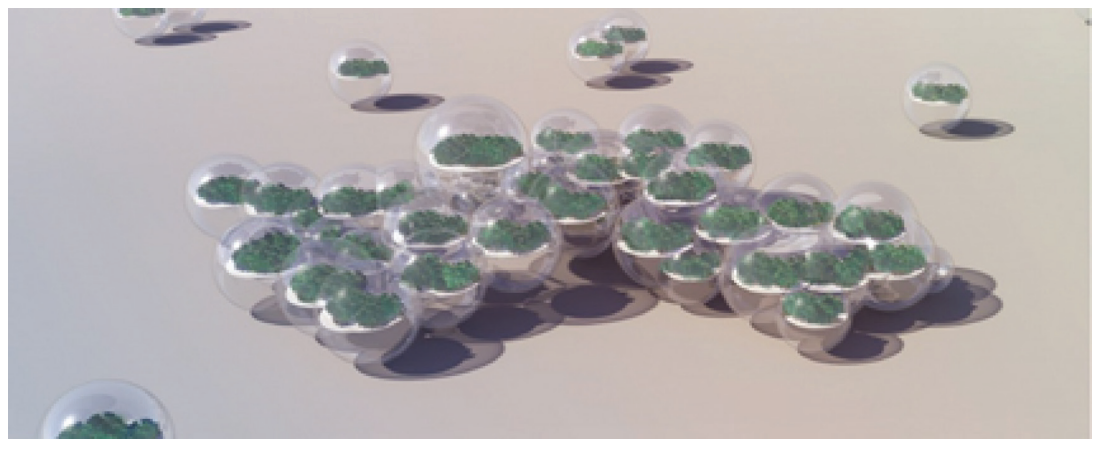

Figure 9: I-City/We-City (the Why Factory, 2012).

design research tries to solve the situation through the creation of 'community clusters', designed to respond to the basic problems, such as food production, waste cycle, energy, etc. These clusters are floating spheres, composed of a hyper-skin with high performance (energy, air pollution, etc.). When each sphere joins other spheres, the I-City evolves in We-City (Fig. 9).

Among the presented approaches, 'retreat' and 'attack' strategies seem to be the most suitable to become strategic advanced urban planning instruments that allow city to respond to the needs in short term. They involve the idea of 'permanent relocation' as management tool useful for enhancing residents' hazard vulnerability in floodplains, earthquake, landslide and volcanos prone areas and as a hazard mitigation measure with natural or technological threats [28-30].

\section{URBAN STRATEGY OF RISK REDUCTION: RELOCATION}

In the last years, relocation becomes more desirable as a mitigation tool when natural risks are high and protection measures are limited in efficacy, safety and feasibility or when the costs are too high. In urban and regional scale, two possible strategies of intervention to reduce the risks are the relocation of a specific urban function from high-risk to low-risk area (Areal change) and the replacement of high exposure functions with lower exposure ones in the same area (Functional change) [31]. 
- Areal change. It acts directly on the physical relocation of different buildings in areas less dangerous: the function keeps unchanged and the planner/designer only defines the use of the abandoned building that should have a lower exposure.

- Functional change. It acts on the function by reducing exposure that implies consequently a reduction of natural risk and physical and economic losses. It is possible to carry out the intervention taking into account the level of compatibility between different uses.

There are at least two solutions: change of function with same building (the functional changes are able to ensure the exposure and crowding's reduction, i.e. from residential to tertiary or from facilities to retail); change of function with significant changes of building (new safer construction that fits better with new function, replaces the previous).

Therefore, it is necessary to define different scenarios to identify the best solution to risk reduction: it is also necessary to analyze the key elements (type of hazard, behavior of citizens, urban fabric with its functions, economic feasibility, anthropological value of places and cultural heritage) of the purpose. This process is well known as Planning Scenario, [32], a strategic planning method suitable for spatial planning because it allows simplifying huge amounts of data in few possible configurations. With its use, it is possible to integrate quantitative data with qualitative expressions and disciplines; the inner fuzziness of many variables that determine the city life and the relationships between the urban actors are not an obstacle because the same method explores the relationship between various uncertainties.

To define the different scenarios, the main closely interrelated steps are: main aim definition; main stakeholders identification; identification if basic trends; identification of critical uncertainties; creation of initial scenario; consistency and plausibility checks; study of scenario's themes; definition of in-depth analysis; development of quantitative models; scenarios and strategies updating.

The inner characteristics of scenario planning perfectly consistent with the approach of flexible, adaptive and resilient city.

\section{CONCLUSION}

The need to adapt urban environment to natural dynamics (slow and relating to long periods, such as climate change, or sudden) leads to identify actions aimed to limit the effects of a hazardous event in a specific territorial, social and economic context. Scenario planning, finalized to analysis and interpretation of interactive processes involving social subjectivity, is the best tool available to ensure a resilient and flexible contribution to the future of the city.

\section{REFERENCES}

[1] UN (United Nations), World Population Prospects. The 2015 Revision Key Findings and Advance Tables, New York, 2015.

[2] IPCC, Climate change 2007: impacts, adaptation and vulnerability. Working group II contribution to the IPCC, fourth assessment report, 2007.

[3] Godschalk, D.R., Urban hazard mitigation: creating resilient cities. Natural Hazards Review, 4:3, pp. 136-143, 2003. http://dx.doi.org/10.1061/(ASCE)1527-6988(2003)4:3(136)

[4] Adger, W.N., Social and ecological resilience: are they related? Progress in Human Geography, 24:3, pp. 347-364, 2000. http://dx.doi.org/10.1191/030913200701540465 
438 Urban Regeneration and Sustainability

[5] IPCC (Intergovernmental Panel on Climate Change), Climate Change 2001: impacts, adaptation and vulnerability. Contribution of working group ii to the fourth assessment report of the intergovernmental panel on climate change, Cambridge University Press, Cambridge, UK, 2001.

[6] Kasperson, J.X. \& Kasperson, R.E., The Social Contours of Risk: Volume II. Risk Analysis, Corporations and the Globalization of Risk, Earthscan: London Sterling, VA, 2005.

[7] UKCIP, Climate adaptation: risk, uncertainty and decision-making (UKCIP Technical report, edited by Willows and Connel), 2003, available at http://www.ukcip.org.uk/

[8] UNISDR (United Nations International Strategy for Disaster Reduction), Terminology: basic terms of disaster risk reduction. International strategy for disaster reduction secretariat, Ginevra, 2004, available at http://www.unisdr.org/eng/libterminology-eng\%20 home.html

[9] Tompkins, E.L. \& Amundsen, H., Perceptions of the effectiveness of the united nations framework convention on climate change in prompting behavioral change. Tyndall Centre Working Paper, 92, 2005.

[10] UNISDR, Global assessment report on disaster risk reduction: revealing risk, redefining development. Geneva, 2011 available at http://www.unisdr.org/we/inform/publications/19846

[11] Rockfeller Foundation, available at https://www.rockefellerfoundation.org/our-work/ topics/resilience/

[12] Foster, H.D., The Ozymandias Principles, Southdowne Press: Victoria, B.C., 1997.

[13] Colucci, A., Le città resilienti: approcci e strategie, Jean Monnet Interregional Centre of Excellence, University of Pavia, 2012.

[14] Hopkins, R., The Transition Handbook. From Oil Dependency to Local Resilience, Green Books Ldt: Devon, UK, 2008.

[15] Lewis, M. \& Conaty, P., The Resilience Imperative: Cooperative Transitions to a Steady-State Economy, Gabriola Island, BC: New Society, 2012.

[16] Thayer, J., Rider, M. \& Lerch, D., Resilient what?: how leading U.S. municipalities are understanding and acting on resilience, Post Carbon Institute, 2013, available at http:// www.postcarbon.org/publications/resilient-against-what/

[17] Jha, A.K., Miner, T.W. \& Stanton-Geddes, Z. (eds), Building Urban Resilience: Principles, Tools and Practice, Directions in Development. Washington, DC: World Bank, 2013. http://dx.doi.org/10.1596/978-0-8213-8865-5

[18] World Bank, Cities and Flooding. A Guide to Integrated Urban Flood Risk Management for the 21st Century, Washington, DC: World Bank/IBDR, 2012.

[19] Zimmerman, R., Resiliency, vulnerability, and criticality of human systems. Research theme from the New York University Workshop on Learning from Urban Disasters, 2001.

[20] Geddes, P., Two steps in Civics: cities and town planning exhibition and international congress of cities. Town Planning Review, 4:2, pp. 78-94, 1913. http://dx.doi.org/10.3828/tpr.4.2.g0x027743vp43033

[21] Choay, F., "Premessa" in Sitte C., L'arte di costruire la città. L'urbanistica secondo isuoi fondamenti artistici, Jaka Book, Milano, pp. 10, 1981.

[22] Welter, V.M., Biopolis. Patrick Geddes and the City of Life, The MIT Press: Cambridge, MA, 2002. 
[23] De Lotto, R., Flexibility principles for contemporary cities. In eds. Shiling, Z. \& Bugatti, A, Changing Shanghai - from Expo's after Use to New Green Towns, Officina Edizioni: Roma, pp. 73-78, 2011.

[24] Morelli di Popolo, C., La città flessibile. Le dimensioni della flessibilità nella città contemporanea e futura, PhD Thesis Degree in Civil and Architectural Engineering, University of Pavia, 2014.

[25] RIBA - Royal Institute of Building Architecture, and ICE - Institute of Civil Engineering, England. Facing Up to Rising Sea Levels - Retreat? Defend? Attack?

[26] Feireiss, L. \& Klanten, R., Utopia forever, Visions of Architecture and Urbanism, Gestalten: Berlin, Germany, 2011.

[27] The Why Factory, available at http://thewhyfactory.com/project/

[28] Mileti, D.S. \& Passerini, E., A social explanation of urban relocation after earthquakes. International Journal of Mass Emergencies and Disaster, 14:1, pp. 97-110, 1996.

[29] Perry, R.W. \& Lindell, M.K., Principles for Managing Community Relocation as a Hazard Mitigation Measure. Journal of Contingencies and Crisis Management, 5:1, pp. 49-49, 1997. http://dx.doi.org/10.1111/1468-5973.00036

[30] Menoni, S. \& Pesaro, G., Is relocation a good answer to prevent risk? Criteria to help decision makers choose candidates for relocation in areas exposed to high hydrogeological hazards. Disaster Prevention and Management, 17:1, pp. 33-53, 2008. http://dx.doi.org/10.1108/09653560810855865

[31] De Lotto, R., Morelli di Popolo, C., Morettini, S. \& Venco, E.M., La valutazione di scenari flessibili per la riduzione del rischio naturale. Planum the Journal of Urbanism, 27:2, 2013.

[32] Schoemaker, P.J.H., Scenario planning: a tool for strategic thinking. Sloan Management Review, 36:2, 1995. 